\title{
Solid contact PVC membrane electrodes based on neutral or charged carriers for the selective reading of anionic sulfamethoxazole and their application to the analysis of aquaculture water
}

\author{
S.A.A. Almeida, A.M. Heitor, L.C. Sá, J. Barbosa, M. da Conceição, \\ B.S.M. Montenegro and M.G.F Sales
}

\begin{abstract}
Sulfamethoxazole (SMX) is among the antibiotics employed in aquaculture for prophylactic and therapeutic reasons. Environmental and food spread may be prevented by controlling its levels in several stages of fish farming. The present work proposes for this purpose new SMX selective electrodes for the potenti- ometric determination of this sulphonamide in water. The selective membranes were made of polyvinyl chloride (PVC) with tetraphenylporphyrin manganese

(III) chloride or cyclodextrin-based acting as ionophores. 2-nitrophenyl octyl ether was employed as plasticizer and tetraoctylammonium, dimethyldioctadecy- lammonium bromide or potassium tetrakis (4chlorophenyl) borate was used as anionic or cationic additive. The best analytical performance was reported for ISEs of tetraphenylporphyrin manganese (III) chloride with $50 \%$ mol of potassium tetrakis (4chlorophenyl) borate compared to ionophore. Nersntian

behaviour was observed from $4.0 \quad 10-5$ t\& $1.0 \quad 10-2 \mathrm{~mol} / \mathrm{L}(10.0$ to $2500 \mathrm{mg} /$

$\mathrm{mL})$, and the limit of detection was $1.2 \quad 10-5 \mathrm{~mol} / \mathrm{L}(3.0 \mathrm{mg} / \mathrm{mL})$. In general, the electrodes displayed steady potentials in the $\mathrm{pH}$ range of 6 to 9. Emf equilibrium

was reached before $15 \mathrm{~s}$ in all concentration levels. The electrodes revealed good discriminating ability in environmental samples. The analytical application to contaminated waters showed recoveries from 96 to $106 \%$.
\end{abstract}

\section{Keywords} porphyrin

Sulfamethoxazole; aquaculture; ion selective electrode; cyclodextrin;

\section{Introduction}

Aquaculture is a food source of great impact on the economy, especially facing the current global economic crisis [1]. However, public health concerns on residues and resistance of antimicrobial agents [1-5] have emerged as aquaculture intensifies and diversifies. The antimicrobials used to treat fish diseases are the same compounds given to humans [6-8]. They contaminate the aquatic environment with excrements and uneaten antibiotic feed $[9,10]$, being able to reach water treatment facilities [11] and increasing the risk of 


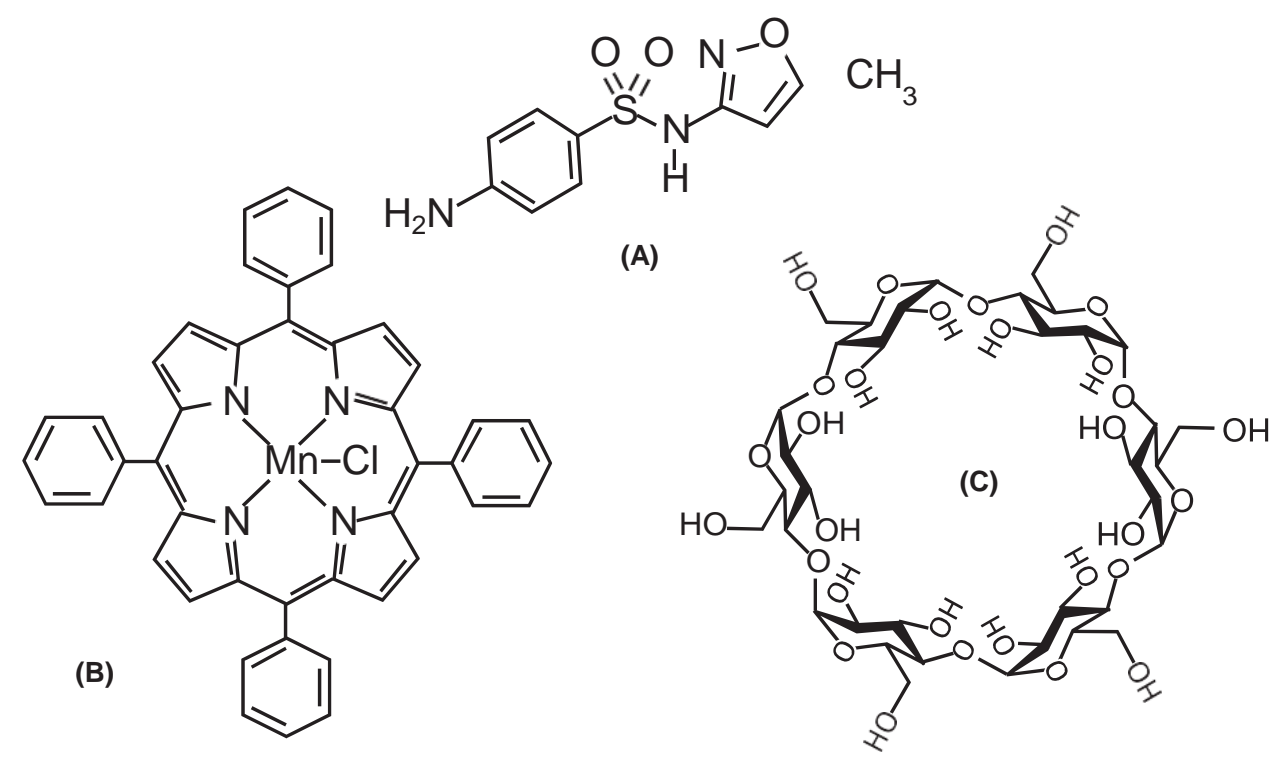

Figure 1. Chemical structures of SMX (A), $\mathrm{Mn}^{\mathrm{III}} \mathrm{TPPCl}(\mathrm{B})$ and $\mathrm{CD}$ (a structure presented).

contamination in drinking water supplies. In addition, the escalating spread of resistance in pathogens $[12,13]$ is today advising restrictions on the veterinary use of antibiotics.

Sulfamethoxazole (SMX) is one of the several antibiotics used in fish farming practices (Figure 1). It is a member of the sulfonamide family of antibiotics that have a high potential to resist degradation [5,14], and acts by inhibiting the utilization of $p$ aminobenzoic acid by bacteria in the synthesis of folic acid [15-17].

To contain the environmental spread of SMX, its levels must be rigorously and continuously controlled in all stages of fish farming. Microbiological and chromatographic methods are employed for this purpose [18], but they are time consuming and too expensive to be used in a routine basis. They are also unable to carry out on-site screening analysis. New simple methods that offer quick and selective readings are thus required. Ideally, this could be achieved by non-destructive and highly selective/sensitive measurements, such as those employing ion-selective electrodes (ISEs). They offer high precision, rapidity, enhanced selectivity and sensitivity over a wide range of concentrations [19].

Ion-selective membrane sensors are able to discriminate selectively the analyte to which they are designed by means of a selective complexation between the target ion (guest) and a specific carrier (host) that is incorporated in the membrane of the electrodes [20]. In general, the overall selectivity of the host guest interaction depends on several factors such as: (i) the cavity of the host should be large enough to accommodate the guest species; (ii) the number of donor atoms in the ligand should be sufficient, to match the coordination number of the target species; (iii) the flexibility of the donor atoms in the host backbone must be limited, so that their positions are suitable to match the shape of the coordination sphere of the target species [21].

SMX binds to positively charged host molecules because it is negatively charged in aqueous media. Thus, a positively charged carrier could be tested as potentiometric ionophore. Electrostatic interactions are however non-directional and other anions my 
bind to form either a solvent-separated or contact-ion pair. As an alternative, neutral host molecules may also be tried out as ionophore. Although the forces between anions and cations are larger, anions also bind to neutral receptors if there is a difference in electrostatic charge [22]. It has been argued that neutral receptors offer the possibility of enhanced selectivity when they turn out invisible for the competing counter-anion. These assumptions justify the application of neutral or charged carrier compounds, such as cyclodextrin (CD) or porphyrin (PPHR) derivatives, respectively, for the potentiometric transduction of anionic species.

In the present work, new potentiometric sensors are proposed for SMX by doping polyvinyl chloride (PVC) membranes with neutral CD or charged PPHR. The effect of positively or negatively charged additives was also studied as the nature/amount of ionophore and additive in the selective membrane affect the analytical performance of ISEs. The response behaviour of all ISEs is reported and compared herein.

\section{Experimental}

\subsection{Apparatus}

The potential build up across the membrane electrode was measured using the galvanic cell as $\mathrm{AgCl}(\mathrm{s}) / \mathrm{Ag}$ double junction reference electrode $\mathrm{jj}$ test solution $\mathrm{j}$ PVC membrane $\mathrm{j}$ Graphite-based conductive support. Emf was measured in a Crison mpH 2002 decimilivoltammeter, using an Orion, 90-00-29, double-junction electrode as reference.

The analytical output signal was transferred to a commutation point reconnecting to one among six ways out. Each way presented an electrical antenna connector compatible to each electrode. The selective electrodes had no internal reference solution and used graphite/epoxy resin as conductive solid contact [23].

The $\mathrm{pH}$ of the solutions was measured by means of a Crison CWL/S7 combined glass electrode connected to a decimilivoltammeter Crison, $\mathrm{pH}$ meter, GLP 22. Spectrophotometric assays were carried out on a Shimadzu Pharmaspec UV-1700.

The LC system (Agilent Technologies, Palo Alto, CA, USA) consisted of an HP1100 thermostatted autosampler, degasser, gradient pump, and thermostatted column, coupled to a Triple Quadrupole System Sciex API 2000 (Applied Biosystem, Foster City, USA) mass detector was used for sample analysis. It was equipped with a Zorbax Eclipse XDB C18, 5 mm, 150x $2.1 \mathrm{~mm}$ column (Agilent Technology, Palo Alto, USA). Data acquisition was controlled by Sciex Analyst ${ }^{\circledR}$ software, version 1.4.1.

\subsection{Reagents and solutions}

All chemicals were of analytical grade and deionised water (conductivity $5 \quad 0.054 \mathrm{mS} / \mathrm{cm}$ at $25^{\circ} \mathrm{C}$ ) was used. SMX, tetraoctylammonium bromide (TOABr), dimethyldioctadecy- lammonium bromide (DDABr), 2-nitrophenyl octyl ether (2-NPOE), potassium tetrakis (4chlorophenyl) borate (KTpClPB), tetrahydrofuran (THF), a-, \{3- or y-CDs, mesotetraphenylporphyrin manganese (III) chloride complex $\left(\mathrm{Mn}^{\mathrm{III}} \mathrm{TPPCl}\right)$, and $\mathrm{PVC}$ of high relative molecular weight were purchased from Sigma-Aldrich (Barcelona, Spain). Formic acid, methanol, acetonitrile were high-performance liquid chromatography (HPLC) grade and purchased from Merck (Darmstadt, Germany).

Stock solutions of SMX were 0.01 M and prepared in water. More diluted standards were prepared by rigorous dilution with buffer. Buffered solutions were prepared in $0.01 \mathrm{M}$ 
4-(2-hydroxyethyl)-1-piperazineethanesulfonic acid (HEPES, Sigma, Barcelona, Spain), pH 5.4

The effect of $\mathrm{pH}$ was studied for a $1.0 \times 10^{-3} \mathrm{M}$ SMX solution. Its $\mathrm{pH}$ was altered by adding either sulphuric acid or sodium hydroxide diluted solutions.

Interference studies relying on the separated solutions method used $1.19 \times 10^{-4}$, $4.94 \times 10^{-4}$ and $1.01 \times 10^{-3} \mathrm{M}$ solutions in SMX or sodium carbonate, sodium chloride, potassium nitrate, sodium nitrite, sodium fluoride, sodium hydrogen carbonate (bicarbonate), sodium citrate, sodium tartrate, sodium acetate, sodium phosphate, sodium borate, sodium cyanide, sodium sulphate and glucose. For the matched potential method, a SMX concentration of $5.9 \times 10^{-5} \mathrm{M}$ or variable concentrations of each interfering species were added to a $7.9 \times 10^{-5} \mathrm{M}$ SMX solution. All solutions were prepared by suitable dissolution/dilution of the corresponding reagents (Merck, Darmstatd, Germany) in buffer.

\subsection{Construction of the SMX selective electrodes}

The solid conductive support was made by mixing Araldite $M$ and hardener in a 1:0.4 $(\mathrm{w} / \mathrm{w})$ ratio. This epoxy resin was then mixed with graphite powder in a $2: 1(\mathrm{w} / \mathrm{w})$ ratio and applied at $0.2 \mathrm{~cm}$ of the end of the electrode body made of Perspex tube (external $\varnothing 12 \mathrm{~mm}$, internal $\varnothing 10 \mathrm{~mm}$, length $15 \mathrm{~cm}$ ).

The selective membrane was prepared by mixing $5.5 \mathrm{mg}$ of active ingredient (CD or PPHR) with $370 \mathrm{mg}$ of plasticizer (2-NPOE) and different amounts of different additives (Table 1). The resulting solutions were added of $180 \mathrm{mg}$ of PVC previously dissolved in about $5 \mathrm{ml}$ THF. After successive applications of the membranes onto the solid conductive support, the different units were left to dry for 2 days at room temperature, guaranteeing the complete evaporation of THF.

\subsection{Potentiometric procedures}

The response characteristics of the coated graphite electrodes were assessed by measuring the emf against increasing concentrations of SMX. This was made at room temperature, according to [24] and following IUPAC recommendations [25]. Aliquots of a $1.0 \times 10^{-3} \mathrm{M}$ SMX aqueous solution ranging from 0.0200 to $10.0 \mathrm{~mL}$ were transferred into $50.0 \mathrm{~mL}$ of electrolyte solution. HEPES solutions of $0.01 \mathrm{M}$ ionic strength were used for this purpose. The solutions were stirred and potential readings recorded after stabilization to $\Perp .2 \mathrm{mV}$. A calibration graph plotted logarithm concentration against emf.

The effect of $\mathrm{pH}$ was evaluated for $1.0 \times 10^{-3} \mathrm{M}$ SMX solution prepared in water. Volumes from 5 to $2000 \mathrm{~mL}$ of saturated $\mathrm{NaOH}$ solution were added to increase the $\mathrm{pH}$ up to 11 . This was followed by the addition of diluted $\mathrm{H}_{2} \mathrm{SO}_{4}$ until the $\mathrm{pH} 3$ was reached. The operational $\mathrm{pH}$ ranges were found for maximum potential variations of $\pm \mathrm{mV}$. The selectivity was assessed by the separated solutions or matched potential methods [26], reading single or mixed analyte compositions of SMX standard or interfering species.

\subsection{Sample preparation}

Various kinds of aquaculture water were sampled from the north region of Portugal. The waters were collected from the tank itself and from the surroundings, in order to estimate 
Table 1. Membrane composition and main analytical features the SMX sensors.

\begin{tabular}{|c|c|c|c|c|c|c|c|c|c|}
\hline \multirow[b]{2}{*}{ ISE } & \multicolumn{4}{|c|}{ Membrane composition } & \multirow{2}{*}{$\begin{array}{c}\text { Slope } \\
\text { (mV/decade) }\end{array}$} & \multirow{2}{*}{$\begin{array}{c}r \\
\left(n^{1 / 44)}\right)\end{array}$} & \multirow{2}{*}{$\begin{array}{c}\text { LLLR } \\
\text { (M) }\end{array}$} & \multirow{2}{*}{$\begin{array}{l}\text { LOD } \\
(\mathrm{M})\end{array}$} & \multirow{2}{*}{$\begin{array}{c}\text { Response } \\
\text { time (s) }\end{array}$} \\
\hline & Active ingredient & Plasticizer & Additive & Weight (mg) & & & & & \\
\hline I & $\mathrm{Mn}^{\mathrm{III}} \mathrm{TPPCl}$ & 2-NPOE & & $5.5: 370$ & $48.79 \pm 1.94$ & 0.9992 & $4.97 \mathrm{E}-05$ & $1.51 \mathrm{E}-05$ & 515 \\
\hline II & $\mathrm{Mn}^{\mathrm{III}} \mathrm{TPPCl}$ & 2-NPOE & $\overline{\mathrm{TOAB}} \mathrm{r}$ & $5.5: 370: 1.1$ & $70.25 \pm 2.91$ & 0.9977 & $3.98 \mathrm{E}-05$ & $1.21 \mathrm{E}-05$ & 515 \\
\hline III & $\mathrm{Mn}^{\mathrm{III}} \mathrm{TPPCl}$ & 2-NPOE & $\mathrm{TOABr}$ & $5.5: 370: 2.1$ & $64.46 \pm 2.09$ & 0.9981 & $2.00 \mathrm{E}-05$ & $6.06 \mathrm{E}-06$ & 515 \\
\hline IV & $\mathrm{Mn}^{\mathrm{III}} \mathrm{TPPCl}$ & 2-NPOE & TOABr & $5.5: 370: 4.3$ & $69.76 \pm 1.73$ & 0.9972 & $2.50 \mathrm{E}-05$ & $7.56 \mathrm{E}-06$ & 515 \\
\hline V & $\mathrm{Mn}^{\mathrm{III}} \mathrm{TPPCl}$ & 2- NPOE & DDABr & $5.5: 370: 1.2$ & $68.35 \pm 1.65$ & 0.9979 & $4.31 \mathrm{E}-05$ & $1.31 \mathrm{E}-05$ & 515 \\
\hline VI & $\mathrm{Mn}^{\mathrm{III}} \mathrm{TPPCl}$ & 2-NPOE & $\mathrm{DDABr}$ & $5.5: 370: 2.4$ & $65.26 \pm 2.09$ & 0.9989 & $3.98 \mathrm{E}-05$ & $1.21 \mathrm{E}-05$ & 515 \\
\hline VII & $\mathrm{Mn}^{\mathrm{III}} \mathrm{TPPCl}$ & 2-NPOE & $\mathrm{DDABr}$ & $5.5: 370: 4.9$ & $64.64 \pm 2.31$ & 0.9988 & $4.97 \mathrm{E}-05$ & $1.51 \mathrm{E}-05$ & 515 \\
\hline VIII & $\mathrm{Mn}^{\mathrm{III}} \mathrm{TPPCl}$ & 2-NPOE & KTpCIPB & $5.5: 370: 1$ & $46.72 \pm 2.51$ & 0.9969 & 4.97 E-05 & $1.51 \mathrm{E}-05$ & 515 \\
\hline IX & $\mathrm{Mn}^{\mathrm{III}} \mathrm{TPPCl}$ & 2-NPOE & KTpCIPB & $5.5: 370: 1.9$ & $58.98 \pm 1.61$ & 0.9952 & 3.98 E-05 & $1.21 \mathrm{E}-05$ & 515 \\
\hline$X$ & $\mathrm{Mn}^{\mathrm{III}} \mathrm{TPPCl}$ & 2-NPOE & KTpCIPB & $5.5: 370: 3.9$ & $70.11 \pm 0.97$ & 0.9976 & $2.00 \mathrm{E}-05$ & $6.06 \mathrm{E}-06$ & 515 \\
\hline XI & $\mathrm{a}-\mathrm{CD}$ & 2-NPOE & & $5.5: 370$ & $24.54 \pm 1.05$ & 0.9974 & 3.98 E-04 & $1.21 \mathrm{E}-04$ & 515 \\
\hline XII & $\mathrm{a}-\mathrm{CD}$ & 2-NPOE & $\mathrm{T} \overline{\mathrm{OAB}} \mathrm{r}$ & $5.5: 370: 0.8$ & $28.61 \pm 1.06$ & 0.9993 & 3.98 E-05 & $1.21 \mathrm{E}-05$ & 515 \\
\hline XIII & $\mathrm{a}-\mathrm{CD}$ & 2-NPOE & TOABr & $5.5: 370: 1.5$ & $56.22 \pm 1.07$ & 0.9979 & 3.98 E-05 & $1.21 \mathrm{E}-05$ & 515 \\
\hline XIV & $\mathrm{a}-\mathrm{CD}$ & 2-NPOE & $\mathrm{TOABr}$ & $5.5: 370: 3.1$ & $59.40 \pm 0.44$ & 0.9983 & 3.98 E-05 & $1.21 \mathrm{E}-05$ & 515 \\
\hline XV & $\mathrm{a}-\mathrm{CD}$ & 2-NPOE & $\mathrm{DDABr}$ & $5.5: 370: 0.9$ & $57.78 \pm 3.24$ & 0.9967 & 6.95 E-05 & 2.11 E-05 & 515 \\
\hline XVI & $\mathrm{a}-\mathrm{CD}$ & 2-NPOE & $\mathrm{DDABr}$ & $5.5: 370: 1.8$ & $62.35 \pm 1.21$ & 0.9970 & 3.49 E-05 & 1.06 E-05 & 515 \\
\hline XVII & $\mathrm{a}-\mathrm{CD}$ & 2-NPOE & $\mathrm{DDABr}$ & $5.5: 370: 3.5$ & $66.33 \pm 2.81$ & 0.9972 & 3.32 E-05 & $1.01 \mathrm{E}-05$ & 515 \\
\hline XVIII & $\mathrm{a}-\mathrm{CD}$ & 2-NPOE & KTрClPB & $5.5: 370: 0.7$ & $20.09 \pm 1.93$ & 0.9965 & 3.98 E-04 & $1.21 \mathrm{E}-04$ & 515 \\
\hline XIX & $\mathrm{a}-\mathrm{CD}$ & 2-NPOE & KTpClPB & $5.5: 370: 1.4$ & $31.50 \pm 2.06$ & 0.9979 & 3.98 E-05 & $1.21 \mathrm{E}-05$ & 515 \\
\hline XX & $\mathrm{a}-\mathrm{CD}$ & 2-NPOE & KTpCIPB & $5.5: 370: 2.8$ & $29.87 \pm 1.20$ & 0.9979 & 3.98 E-05 & $1.21 \mathrm{E}-05$ & 515 \\
\hline XXI & $\{3-C D$ & 2-NPOE & & $5.5: 370$ & $24.36 \pm 2.52$ & 0.9967 & 3.97 E-04 & $1.20 \mathrm{E}-04$ & 515 \\
\hline XXII & $\{3-C D$ & 2-NPOE & $\mathrm{T} \overline{\mathrm{OAB}} \mathrm{r}$ & $5.5: 370: 0.6$ & $57.72 \pm 2.05$ & 0.9975 & 3.97 E-05 & $1.20 \mathrm{E}-05$ & 515 \\
\hline XXIII & $\{3 \mathrm{CD}$ & 2-NPOE & TOABr & $5.5: 370: 1.3$ & $58.71 \pm 0.77$ & 0.9971 & 3.97 E-05 & $1.20 \mathrm{E}-05$ & 515 \\
\hline XXIV & $\{3-C D$ & 2-NPOE & $\mathrm{TOABr}$ & $5.5: 370: 2.6$ & $59.16 \pm 1.20$ & 0.9967 & $2.98 \mathrm{E}-05$ & 9.03 E-06 & 515 \\
\hline XXV & $\{3-C D$ & 2-NPOE & $\mathrm{DDABr}$ & $5.5: 370: 0.7$ & $52.54 \pm 2.26$ & 0.9974 & 3.91 E-05 & $1.18 \mathrm{E}-05$ & 515 \\
\hline XXVI & $\{3-C D$ & 2-NPOE & DDABr & $5.5: 370: 1.5$ & $55.58 \pm 2.31$ & 0.9979 & 3.91 E-05 & $1.18 \mathrm{E}-05$ & 515 \\
\hline XXVII & $\{3-C D$ & 2-NPOE & $\mathrm{DDABr}$ & $5.5: 370: 3.1$ & $49.66 \pm 2.23$ & 0.9990 & 3.42 E-05 & 1.04 E-05 & 515 \\
\hline XXVIII & $\{3-C D$ & 2-NPOE & KTpCIPB & $5.5: 370: 0.6$ & $20.80 \pm 1.18$ & 0.9984 & 1.26 E-04 & 3.82 E-05 & 515 \\
\hline XXIX & $\{3-C D$ & 2-NPOE & KTрClPB & $5.5: 370: 1.2$ & $23.16 \pm 0.97$ & 0.9979 & 2.34 E-04 & 7.09 E-05 & 515 \\
\hline
\end{tabular}


Table 1. Continued.

\begin{tabular}{|c|c|c|c|c|c|c|c|c|c|}
\hline \multirow[b]{2}{*}{ ISE } & \multicolumn{4}{|c|}{ Membrane composition } & \multirow{2}{*}{$\begin{array}{c}\text { Slope } \\
\text { (mV/decade) }\end{array}$} & \multirow{2}{*}{$\begin{array}{c}r \\
(n 1 / 44)\end{array}$} & \multirow{2}{*}{$\begin{array}{c}\text { LLLR } \\
\text { (M) }\end{array}$} & \multirow{2}{*}{$\begin{array}{l}\text { LOD } \\
(\mathrm{M})\end{array}$} & \multirow{2}{*}{$\begin{array}{l}\text { Response } \\
\text { time (s) }\end{array}$} \\
\hline & Active ingredient & Plasticizer & Additive & Weight (mg) & & & & & \\
\hline XXX & $\{3-C D$ & 2-NPOE & KTpCIPB & $5.5: 370: 2.4$ & $29.36 \pm 0.26$ & 0.9980 & $2.34 \mathrm{E}-05$ & $7.09 \mathrm{E}-06$ & 515 \\
\hline XXXI & $y-C D$ & 2-NPOE & & $5.5: 370$ & $24.97 \pm 1.03$ & 0.9960 & $3.98 \mathrm{E}-04$ & $1.21 \mathrm{E}-04$ & 515 \\
\hline XXXII & $\mathrm{y}-\mathrm{CD}$ & 2-NPOE & $\mathrm{TOAB} r$ & $5.5: 370: 0.6$ & $58.71 \pm 0.77$ & 0.9968 & $3.42 \mathrm{E}-05$ & $1.04 \mathrm{E}-05$ & 515 \\
\hline XXXIII & $y-C D$ & 2-NPOE & $\mathrm{TOABr}$ & $5.5: 370: 1.2$ & $57.78 \pm 0.40$ & 0.9983 & $3.42 \mathrm{E}-05$ & $1.04 \mathrm{E}-05$ & 515 \\
\hline XXXIV & $y-C D$ & 2-NPOE & $\mathrm{TOABr}$ & $5.5: 370: 2.3$ & $61.23 \pm 1.26$ & 0.9981 & $3.42 \mathrm{E}-05$ & $1.04 \mathrm{E}-05$ & 515 \\
\hline XXXV & $y-C D$ & 2-NPOE & $\mathrm{DDABr}$ & $5.5: 370: 0.7$ & $56.03 \pm 2.25$ & 0.9974 & $3.91 \mathrm{E}-05$ & $1.18 \mathrm{E}-05$ & 515 \\
\hline XXXVI & $\mathrm{y}-\mathrm{CD}$ & 2-NPOE & $\mathrm{DDABr}$ & $5.5: 370: 1.3$ & $61.08 \pm 1.72$ & 0.9976 & $3.91 \mathrm{E}-05$ & $1.18 \mathrm{E}-05$ & 515 \\
\hline XXXVII & $y-C D$ & 2-NPOE & DDABr & $5.5: 370: 2.7$ & $61.21 \pm 0.37$ & 0.9967 & 2.94 E-05 & 8.89 E-06 & 515 \\
\hline XXXVIII & $\mathrm{y}-\mathrm{CD}$ & 2-NPOE & KTpCIPB & $5.5: 370: 0.5$ & $21.93 \pm 1.21$ & 0.9962 & $1.26 \mathrm{E}-03$ & 3.82 E-04 & 515 \\
\hline XXXIX & $y-C D$ & 2-NPOE & KTpCIPB & $5.5: 370: 1.0$ & $25.52 \pm 1.01$ & 0.9971 & $1.26 \mathrm{E}-04$ & $3.82 \mathrm{E}-05$ & 515 \\
\hline $\mathrm{XL}$ & $y-C D$ & 2-NPOE & KTpClPB & $5.5: 370: 2.1$ & $26.86 \pm 0.56$ & 0.9973 & $1.26 \mathrm{E}-04$ & 3.82 E-05 & 515 \\
\hline
\end{tabular}

LOD: Limit Of Detection; LLLR: Lower Limit of Linear Range. 
antibiotic dissemination. All samples were collected in duplicate in amber glass bottles with polypropylene open-top screw caps and Teflon-silicon septa. All sampling personnel were latex gloves when collecting samples, and changed gloves between sites. After collection, the samples were labelled, wrapped with Parafilm ${ }^{\circledR}$, and immediately chilled and sent to the laboratory.

\subsection{Sample analysis}

The direct potential method was applied to determine SMX in the previous water samples. The electrodes were calibrated prior to potentiometric analysis. The analytical results were compared with those obtained by LC-MS-MS procedures.

A binary gradient phase was used for LC-MS/MS analysis, at a flow rate of $0.35 \mathrm{~mL} / \mathrm{min}$, with $0,1 \%$ formic acid (A) and acetonitrile (B). The gradient starts with $90 \%$ of (A) and goes linearly to $10 \%$ in $15 \mathrm{~min}$, finishing at $90 \%$ of (A) during 1 min with a total run time of $16 \mathrm{~min}$. Sample injection volume was $5 \mathrm{ml}$ and the temperature oven set to $40^{\circ} \mathrm{C}$.

The mass spectrometer was operated in positive electrospray ionisation mode using the TurbolonSpray source. Nitrogen was used for curtain gas, collision gas and nebulizer gas at flow rates of 7, 4 and $9 \mathrm{~L} / \mathrm{min}$. The ion source block temperature was set to $450{ }^{\circ} \mathrm{C}$, and the electrospray capillary voltage to $5.0 \mathrm{kV}$. Data acquisition was performed in the multiple reaction monitoring (MRM) mode. The precursor was $254 \mathrm{~m} / \mathrm{z}$ and the product ions were 156 and $92 \mathrm{~m} / \mathrm{z}$. Collision energy were $23.35 \mathrm{eV}$. The dwell time was set to 100 msec for all the analytes.

SMX stock solutions were prepared by dissolving $10.00 \mathrm{mg}$ of standard in $10 \mathrm{~mL}$ methanol resulting in $1.0 \mathrm{mg} / \mathrm{mL}$ stock solution. This solution was kept at $-80^{\circ} \mathrm{C}$. A working standard solution of SMX was prepared at the concentration of $250 \mathrm{mg} / \mathrm{mL}$ in $\mathrm{MeOH}: \mathrm{H}_{2} \mathrm{O}$ (1:4). This working standard solution was used to prepare the calibration curve. These were evenly distributed into four concentrations between 25 and $250 \mathrm{mg} / \mathrm{mL}$. Sampling volumes of $5 \mathrm{~mL}$ were analyzed in two replicates.

\section{Results and discussion}

SMX sensors were casted over solid contact devices. This configuration helps further miniaturization in subsequent studies and avoids sample contamination by traditional internal reference solutions [27]. Graphite/epoxy resin was selected for solid contact, as coated-wire versions present random drift, attributed to the formation of a thin aqueous layer between the polymeric ion-selective membrane and the inner metal electrode [28].

In general, the sensitivity, selectivity, working range, and stability of an ion-selective electrode depend not only on the nature of the ionophore, but also on the nature and amount of the plasticizer and lipophilic additives. 2-NPOE was selected for plasticizer because previous works showed enhanced sensitivity and selectivity when this solvent was employed [29,30]. The effect of the additive and kind of ionophore is reported here by preparing electrodes with different compositions (Table 1). The electroactive material employed was either of PPHR ( $\left.\mathrm{Mn}^{\mathrm{III}} \mathrm{TPPCl}\right)$ or of $\mathrm{CD}(\mathrm{a}-\mathrm{CD},\{3-\mathrm{CD}$, or $\mathrm{y}-\mathrm{CD})$ nature, doped or not with different lipophilic additives of positive or negative charge. 
(1)

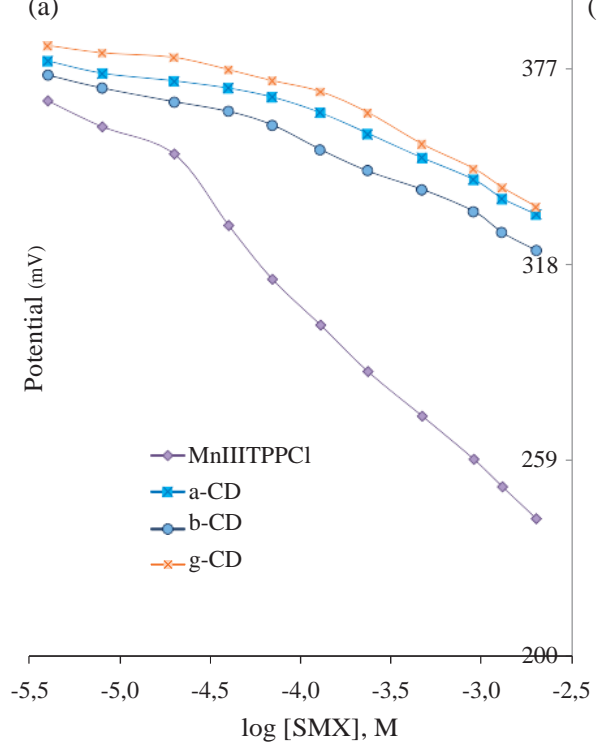

(b)

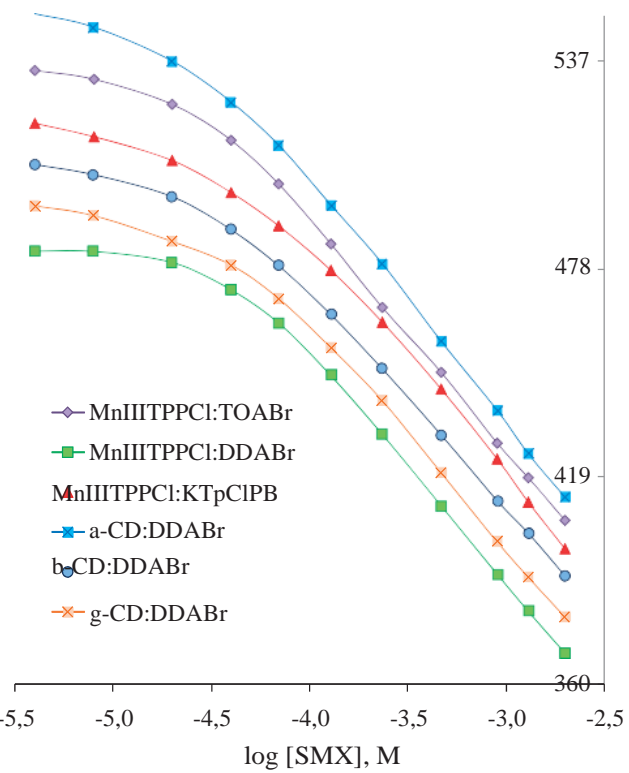

Figure 2. Typical calibration curves of SMX membranes prepared without (left) or with (right) ionic additives.

\subsection{Porphyrin-based sensors}

The selective response of the PPHR-based sensor for SMX was evaluated in plasticized PVC membranes with 1 wt.\% ionophore, 66 wt.\% 2-NPOE, and 33 wt.\% PVC. The PPHR-based ionophore acted as anion carrier because it had a Lewis acidic metal as coordinating site. According to the literature, the nature of the ionophore-anion interaction is strongly influenced by the charge of the central metal ion from the porphyrin structure. The phorphyrin used was coordinated by Mn (III) meaning that it could act either as charged or as neutral carrier. The results suggested that a charged carrier mechanism governed the electrode performance because no charged additive was required to obtain a near-Nernstian behavior. The sensors exhibited a linear correlation of emf against $\log [\mathrm{SMX}, \mathrm{M}]$ (Figure 2, Left) from $5.0 \times 10^{-5}$ to $1.0 \times 10^{-2} \mathrm{M}$, with average slopes of $49 \mathrm{mV} /$ decade. The response of the electrodes was also further enhanced by the addition of positively charged derivatives, which supported the charged carrier mechanism of the potentiometric transduction.

The binding between SMX and $\mathrm{Mn}^{\mathrm{III}} \mathrm{TPPCl}$ was confirmed by spectrophotometric studies. A slight deviation was recorded in the maximum wavelength of $\mathrm{Mn}^{\text {III }} \mathrm{TPPCl}$ absorption spectra when SMX was present. Furthermore, the absorbance values of a blank PPHR solution decreased in the presence of SMX, in agreement with the linear correlation: Absorbance 1/4127 [SMXX, M] 0.066 $\mathrm{k} r$ 0.9971)/4 This correlation was observed between $2.9 \quad 10^{-7}$ and $1.3 \quad 10^{-6} \mathrm{M}$ The binding constant was calculated by the sandwich method. The average value obtained was 4.5 for $\mathrm{Mn}^{\mathrm{III}} \mathrm{TPPCl}$ acting as guest molecule.

Although some concerns have been reported previously about the spontaneous hydroxyl-bridged dimmer formation of metalloporphyrins in ion-selective membranes originating super-Nernstian response slopes [31-33], this was not observed in the present studies. 


\subsection{Cyclodextrin-based sensors}

CDs contain a hydrophilic outer surface and a hydrophobic cavity that may entrap hydrophobic molecules by means of electrostatic interactions. The inclusion complexes between ligand and $\mathrm{CD}$ are a result of hydrophobic and polar interactions established between these [34]. The size of the CD cavity also affects the formation of these inclusion complexes. Three major types of CDs are known, a-, \{3- and y-CD; the a-CD contains six, \{3-CD seven, and y-CD eight glucose units. A general trend is that hydrophobic organic compounds with a relatively small molecular volume form the strongest complexes with a$\mathrm{CD}$ and the weakest with y-CD [35]. The binding constant between SMX and \{3-CDs obtained by the sandwich method was 5.8, a similar value to that obtained when PPHR was used.

When SMX was used as ligand, none of the CD sensors prepared with either a-, \{3-and $\mathrm{y}-\mathrm{CD}$ and plasticized PVC (Table 1) was able to produce a suitable emf variation with SMX concentration (Figure 2, left). The uncharged carriers were neutral when uncomplexed in the membrane and the complexes had the same charge as the analyte ion. Thus, the respective membranes required lipophilic ions of opposite charge to ensure permselectivity [36].

\subsection{Effect of additive}

The effect of positive or negative charged sites in the selective membranes was investigated by doping them with $\mathrm{DDABr}, \mathrm{TOABr}$ or KTpClPB. The ionophore:additive ratio tested was 1:1, 1:0.5 and 1:0.25 (mol:mol), with the additive relative amount changing from 25 to $100 \%$ mol (relative to the ionophore).

For PPHR materials, the cationic additives produced super-Nernstian behaviour, with slopes ranging from 66 to $70 \mathrm{mV} /$ decade (Table 1). In general, the other operating features were unaffected. The electrodes prepared with an ionic additive displayed different behaviour according to the amount of additive. Sub-Nernstian behaviour was observed for a $25 \%$ mol of KTpCIPB while super-Nernstian behaviour was obtained for the $100 \%$ mol additive (equal parts of additive and ionophore). The membranes with $50 \%$ mol amount of additive presented the best performance, with theoretical slopes and linear concentration ranges starting in $4 \times 10^{-5} \mathrm{M}$. The use of an anionic additive may also provide advantages in terms of selectivity, because it acts as an anionic excluder in the membrane, reducing the interference from concomitant anionic species in real samples.

For CD based sensors, the addition of anionic additives gave slopes $532 \mathrm{mV} / \mathrm{decade}$, which supported the fact that the CD ionophores acted as neutral carriers of SMX in the membrane. The cationic additives affected the anionic response to SMX depending on the size of the cavity of the carrier. Nernstian slopes were achieved with DDABr or TOABr when a-CD or $\{3-C D$ was used as ionophore, respectively. For $y-C D$, presenting the largest cavity for SMX inclusion, both cationic additives could be used, enabling suitable and similar analytical features in the potentiometric devices.

In general, ISEs IX and XXXVI exhibited the best analytical features. The slopes were 60.2 and $61.1 \mathrm{mV}$ per decade concentration with the usable concentration range from $2.0 \times 10^{-5}$ to $1.0 \times 10^{-2}$ and $3.9 \times 10^{-5}$ to $1.0 \times 10^{-2}$, respectively. The detection limit was $6.0 \times 10^{-6}$ and $1.2 \times 10^{-5}$, respectively and the response time always :S $15 \mathrm{~s}$ (Figure 2). These electrodes were thus selected in most of the following experiments. To enable a systematic study of the additive effect upon the other analytical features to be studied, CD 
electrodes with 50\% mol of DDABr and PPHR-based electrodes with each additive in $50 \%$ mol were included along the following studies.

\subsection{Effect of $p H$}

The effect of $\mathrm{pH}$ upon the potentiometric response was tested by measuring the emf changes of a $1.0 \times 10^{-3} \mathrm{M} \mathrm{SMX}$ solution over the $\mathrm{pH}$ range of 3 to 11 (Figure 3 ). The $\mathrm{pH}$ was altered by adding diluted $\mathrm{H}_{2} \mathrm{SO}_{4}$ or saturated $\mathrm{NaOH}$ hydroxide solutions and measuring continuously the resulting $\mathrm{pH}$ by a combined glass electrode dipped in the same solution.

In general, the small potential drop for higher $\mathrm{pHs}$ was evident in electrodes with cationic additives, which could suggest a hydroxyl interference. On the contrary, the increasing emf in the acidic range could indicate the lower concentration of anionic SMX in the solution.

The results showed that the operational $\mathrm{pH}$ ranges depended on the ionophore and the additive. PPHR ionophores showed a more intense dependence on the $\mathrm{pH}$ of the solution than CDs. For PPHR sensors with DDABr and TOABr cationic additives, steady emf was obtained within 6-9 and 5.5-9.5, respectively. For anionic additives the sensors behaved like a $\mathrm{pH}$ electrode, turning out selective to $\mathrm{H}^{\mathrm{b}}$. For $\mathrm{CD}$ sensors the increase in the cavity

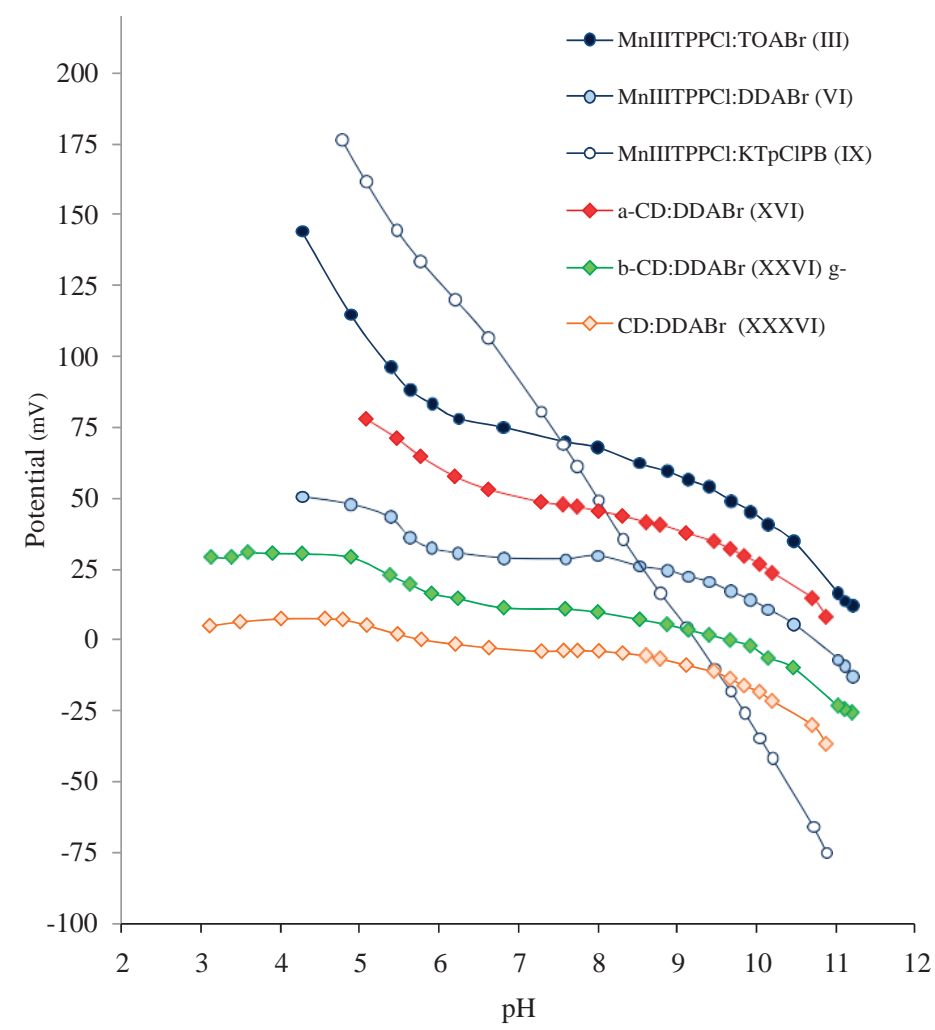

Figure 3. Emf variations of SMX selective electrodes against the $\mathrm{pH}$ of a $1 \times 10^{-3} \mathrm{M}$ SMX solution. 
size originated wider operational $\mathrm{pH}$ range (Figure 3). Thus, $\mathrm{y}-\mathrm{CD}$ was the less affected by $\mathrm{pH}$, with an operational $\mathrm{pH}$ range lying within 3-9.

\subsection{Selectivity of the electrodes}

The selectivity was initially assessed by the separate solutions method (SSM) [37]. The potential was measured with two separate solutions, one containing the SMX ion of activity $a_{S M X}$ (but no interfering species) and the other containing the interfering ion $\mathrm{J}$ of the same activity $a_{S M X} 1 / 4 a_{J}$ (but no SMX anion). The equation applied was:

$$
K_{S M X, J}^{P O T}=a_{S M X}^{\left(1-1 / Z_{J}\right)} e^{\left(E_{J}-E_{S M X}\right) / S}
$$

where the potential values were expressed as $E_{\mathrm{SMX}}$ and $E_{J}$, respectively; $K^{P O T}{ }_{S M X, J}$

was the corresponding potentiometric selectivity coefficient; and $Z_{J}$ the ionic charge of the interfering ion.

All $K_{S M X, J}^{P O T}$ data obtained were expressed in $\log K_{S M X, J}^{P O T}($ Ttable 2). Lower interference was observed for more negative values. In general, the electrode was capable to discriminate SMX against other inorganic anions. The results indicated the following relative order of interference: carbonate shloride, nitrite; hydrogenocarbonate and fluoride interference depended on the electrode in use. The observed series deviated from the Hofmeister pattern, suggesting that the electrode selectivity for anions was not governed by anion lipophilicity. In the present case it seemed to depend on specific chemical interactions between the ionophores and the anions in the sample solution.

The matched potential method (MPM) was also employed to test the feasibility of using the electrodes on the analysis of real samples. In this method, $K_{S M X, J}^{P O T}$ is the activity ratio of primary and interfering ions that give the same potential change under identical conditions. A known activity of SMX $\left(a_{S M X}^{0}\right)$ is added into a solution containing a fixed activity of SMX $\left(a_{S M X}\right)$, and the corresponding potential change $(\mathrm{DE})$ is recorded. A solution of interfering ion is added after to another reference solution of $a_{S M X}$, until the same potential change $\mathrm{D} E$ is obtained. The selectivity coefficient is calculated by:

$$
K_{S M X, J}^{P O T}=\left(a_{S M X}^{\prime}-a_{S M X}\right) / a_{J}
$$

Table 2. Selectivity coefficients for SMX selective electrodes for various interfering ions using separate solution method.

\begin{tabular}{lllllrl}
\hline & \multicolumn{7}{c}{$\log K_{S M X, j^{z^{-}}}^{P O T}$} \\
\cline { 2 - 7 } ISE & $\mathrm{CO}_{3}^{2-}$ & $\mathrm{Cl}^{-}$ & $\mathrm{F}^{-}$ & $\mathrm{HCO}_{3}^{-}$ & $\mathrm{NO}_{3}^{-}$ & $\mathrm{NO}_{2}^{-}$ \\
\hline III & -2.68 & -0.963 & -1.59 & -1.29 & 0.33 & -0.56 \\
VI & -2.86 & -0.953 & -1.54 & -1.19 & -0.41 & -0.92 \\
IX & -1.77 & -0.51 & -0.83 & -0.39 & -1.32 & -0.46 \\
XIII & -2.85 & -1.14 & -1.87 & -1.32 & 0.35 & -0.75 \\
XVI & -1.59 & -1.30 & -1.44 & -0.39 & -0.64 & -1.31 \\
XIX & -2.97 & -1.81 & 0.39 & -1.76 & 0.21 & -1.44 \\
XXIII & -2.79 & -1.20 & -1.73 & -1.40 & 0.45 & -0.72 \\
XXVI & -2.79 & -1.07 & -1.48 & -1.34 & 0.28 & -0.81 \\
XXXIII & -2.93 & -1.18 & -1.84 & -1.61 & 0.44 & -0.79 \\
XXXVI & -2.28 & -0.80 & -1.33 & -1.13 & 0.34 & -0.67 \\
\hline
\end{tabular}


Table 3. Selectivity data for SMX selective electrodes for various interfering ions using both Separate solution (SSM) and Matched Solution (MSM) methods.

\begin{tabular}{lccccc}
\hline & \multicolumn{2}{c}{ SSM } & & \multicolumn{2}{c}{ MPM } \\
\cline { 2 - 3 } \cline { 5 - 6 } Interfering & ISE IX & ISE XXXVI & & ISE IX & ISE XXXVI \\
\hline Acetate & -1.31 & -1.69 & & -0.77 & -0.76 \\
Rorate & -3.08 & 0.2 .89 & & -0.62 & -0.65 \\
Cyanide & -1.25 & -1.75 & & -0.57 & -0.57 \\
Citrate & -2.86 & -3.14 & & -0.50 & -0.51 \\
Phosphate & -3.74 & -3.65 & & -0.70 & -0.72 \\
Glucose & -1.59 & -1.79 & & -0.60 & -0.69 \\
Sulphate & -3.43 & -2.91 & & -0.48 & -0.54 \\
Tartrate & -2.90 & -3.10 & & -0.53 & -0.47 \\
\hline
\end{tabular}

The electrodes used for this purpose were ISEs IX and XXXVI for combining the best analytical features for a practical application: high sensitivity, extended linear range and good selectivity. The anionic species selected for this study were acetate, borate, cyanide, citrate, glucose, phosphate, sulphate and tartrate. In general, the obtained $\log K^{\mathrm{POT}}$ confirmed the preference of the electrodes for SMX over other interfering species (Table 3). All $\log K^{\mathrm{POT}}$ values were negative and confined to a narrow range: -0.47 to -0.77 . The relative order of tolerance levels for the proposed sensor was: Sulphate, Citrate, Tartrate 4 Cyanide 4 Glucose, Borate 4 Phosphate 4 Acetate. The SSM gave $\operatorname{lower} \log K^{\mathrm{POT}}$ values than the MPM, which is logical because primary and interfering ion are competing for the same phenomenon in this last method.

\subsection{Response time and lifetime}

The response time was measured by placing the electrodes in a SMX standard solution and increasing the concentration in about tenfold, from $4.0 \times 10^{-5}$ to $1.0 \times 10^{-3} \mathrm{M}$. The static response time thus obtained was $7 \mathrm{~s}$ for $1.0 \times 10^{-3} \mathrm{M} \mathrm{SMX}$. At lower concentrations, the response time was longer and reached $15 \mathrm{~s}$ for a SMX concentration of $1.0 \times 10^{-4} \mathrm{M}$. The actual potential $v s$. time plot is shown in Figure 4.

In general, the potentials remained constant for approximately 3 min, after which a small deviation was detected. The behaviour of the membrane did not depend on whether the potentials were recorded from low to high concentration or vice versa.

Every kind of electrodes was tested over a period of about two months. During this period each electrode was used daily and stored in $1.0 \times 10^{-6} \mathrm{M}$ SMX solution when not in use. No significant changes in the performance of the electrodes (slopes and linear range) were observed during this period.

\subsection{Analysis aquaculture waters}

The proposed method was applied to determine SMX in water samples from aquaculture environment. The collected samples were confirmed as blank and spiked with 35-340 mg/ $\mathrm{mL}$ of SMX. The electrodes used for this purpose were ISEs IX and XXXVI for displaying 


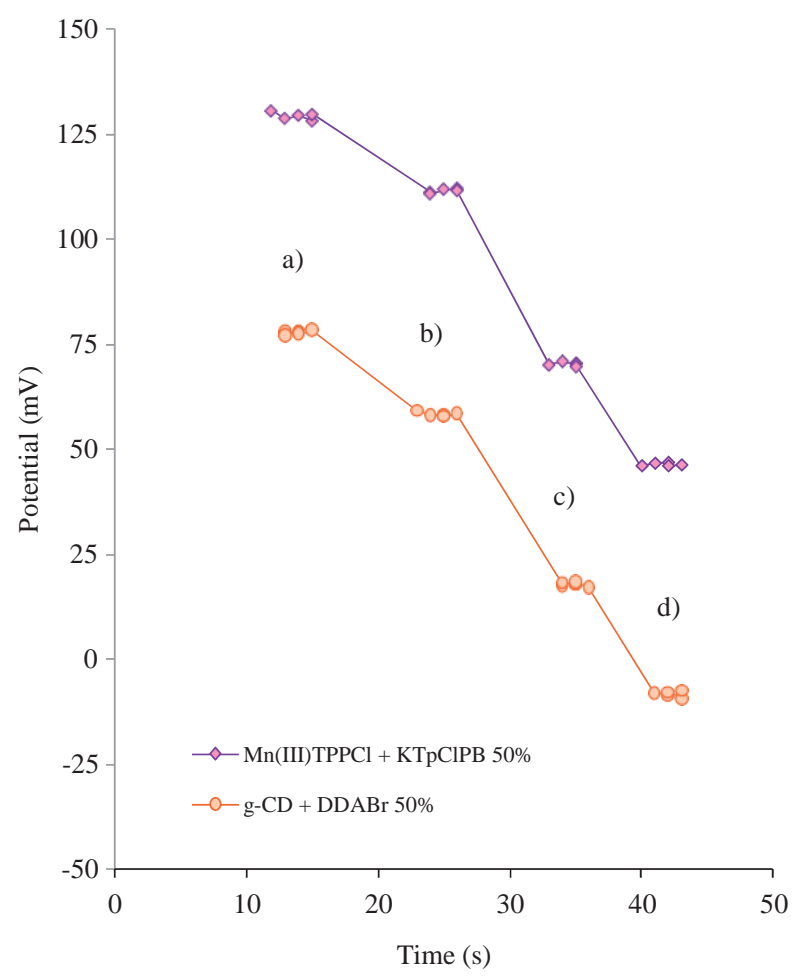

Figure 4. Response time for step changes in concentration of SMX: (a) $4 \times 10^{-5} \mathrm{M}$, (b) $1 \times 10^{-4} \mathrm{M}$, (c) $5 \times 10^{-3} \mathrm{M}$, (d) $1 \times 10^{-3} \mathrm{M}$.

the better analytical features in terms of sensitivity, linear range and selectivity (see Table 1).

The obtained results are summarized in Table 4 and correspond to the mean of at least 3 independent determinations. A good agreement was found between added and found amounts of SMX. The potentiometric set of results showed recoveries ranging from 96 to $106 \%$, which corresponded to relative errors within 3.9 and $5.9 \%$. They were also precise, with relative standard deviations always below $6 \%$. The $t$-student test confirmed that there were no significant differences between the means of added amounts and potentiometric sets of results (Tables 3 and 4). The $p$ value was 0.03 and 0.77 for $\mathrm{Mn}$ (III) PPHR or y-CD sensors, always below the critical value (2.07).

The potentiometric data were validated against an LC-MS/MS method. For this purpose, some of the samples were tested again by both methods. A typical chromatogram for SMX is presented in Figure 5, with a retention time of $13.72 \mathrm{~min}$. The results obtained are indicated in Table 5 and suggest the accuracy and precision of both methods. Using the LC-MS/MS procedure as reference, the $t$ student $\left(p^{1 / 40.33)}\right.$ was below the critical one (2.20), thus confirming the accuracy of all data.

The above results pointed out that the composition of the water samples collected from aquaculture environment did not interfere in the potentiometric determination of SMX. So, the samples were further analyzed with regard to their main composition; the legal parametric data applied to environmental waters were selected for this purpose [38]. The obtained values are indicated in Table 6 , where the minimum as maximum values have 
Table 4. Determination of SMX in aquaculture by potentiometric method, using PPHR and $\mathrm{y}$-CD electrodes.

\begin{tabular}{|c|c|c|c|c|c|}
\hline \multirow[b]{2}{*}{ Sample } & \multirow[b]{2}{*}{ Added, mg/mL } & \multicolumn{2}{|c|}{ PPHR ISE $(n 1 / 43)$} & \multicolumn{2}{|c|}{$y-C D$} \\
\hline & & $\mathrm{SMX}, \mathrm{mg} / \mathrm{mL}$ & $\mathrm{RD}(\%)$ & $\mathrm{SMX}, \mathrm{mg} / \mathrm{mL}$ & $\mathrm{RD}(\%)$ \\
\hline \multirow[t]{4}{*}{1} & 35.0 & $32.8 \pm 0.8$ & 5.9 & $34.9 \pm 0.8$ & -0.3 \\
\hline & 83.3 & $83.1 \pm 3.3$ & 0.2 & $82.3 \pm 0.7$ & -1.2 \\
\hline & 174.6 & $177.0 \pm 5.2$ & -1.4 & $180.8 \pm 3.0$ & 3.5 \\
\hline & 338.1 & $339.5 \pm 12.3$ & -0.4 & $329.6 \pm 5.4$ & -2.5 \\
\hline \multirow[t]{4}{*}{2} & 35.0 & $33.6 \pm 2.0$ & 3.9 & $35.9 \pm 0.5$ & 2.5 \\
\hline & 83.3 & $81.6 \pm 2.4$ & 2.1 & $82.7 \pm 1.7$ & -0.7 \\
\hline & 174.6 & $172.6 \pm 5.8$ & 1.2 & $174.2 \pm 6.0$ & -0.2 \\
\hline & 338.1 & $329.3 \pm 4.1$ & 2.6 & $330.9 \pm 2.3$ & -2.2 \\
\hline \multirow[t]{4}{*}{3} & 35.0 & $33.7 \pm 0.3$ & 3.7 & $36.8 \pm 0.8$ & 5.2 \\
\hline & 83.3 & $84.4 \pm 2.9$ & -1.3 & $82.0 \pm 2.3$ & -1.5 \\
\hline & 174.6 & $173.6 \pm 7.9$ & 0.6 & $180.3 \pm 2.7$ & 3.3 \\
\hline & 338.1 & $330.1 \pm 2.7$ & 2.4 & $333.6 \pm 3.3$ & -1.4 \\
\hline \multirow[t]{4}{*}{4} & 35.0 & $34.4 \pm 0.9$ & 1.6 & $36.5 \pm 1.6$ & 4.3 \\
\hline & 83.3 & $83.0 \pm 1.4$ & 0.4 & $82.4 \pm 2.8$ & -1.1 \\
\hline & 174.6 & $172.1 \pm 0.8$ & 1.4 & $182.1 \pm 2.3$ & 4.3 \\
\hline & 338.1 & $330.6 \pm 7.8$ & 2.2 & $344.2 \pm 17.3$ & 1.8 \\
\hline \multirow[t]{4}{*}{5} & 35.0 & $35.8 \pm 0.9$ & -2.4 & $34.2 \pm 1.0$ & -2.3 \\
\hline & 83.3 & $81.9 \pm 0.5$ & 1.7 & $81.4 \pm 1.7$ & -2.2 \\
\hline & 174.6 & $175.5 \pm 6.3$ & -0.5 & $178.9 \pm 4.1$ & 2.5 \\
\hline & 338.1 & $334.8 \pm 6.7$ & 1.0 & $329.9 \pm 1.6$ & -2.4 \\
\hline \multirow[t]{4}{*}{6} & 35.0 & $34.8 \pm 0.3$ & 0.5 & $35.3 \pm 1.2$ & 1.0 \\
\hline & 83.3 & $84.0 \pm 1.4$ & -0.8 & $82.1 \pm 1.4$ & -1.5 \\
\hline & 174.6 & $176.1 \pm 4.2$ & -0.9 & $177.7 \pm 2.5$ & 1.8 \\
\hline & 338.1 & $331.1 \pm 10.0$ & 2.1 & $331.1 \pm 7.5$ & -2.1 \\
\hline
\end{tabular}

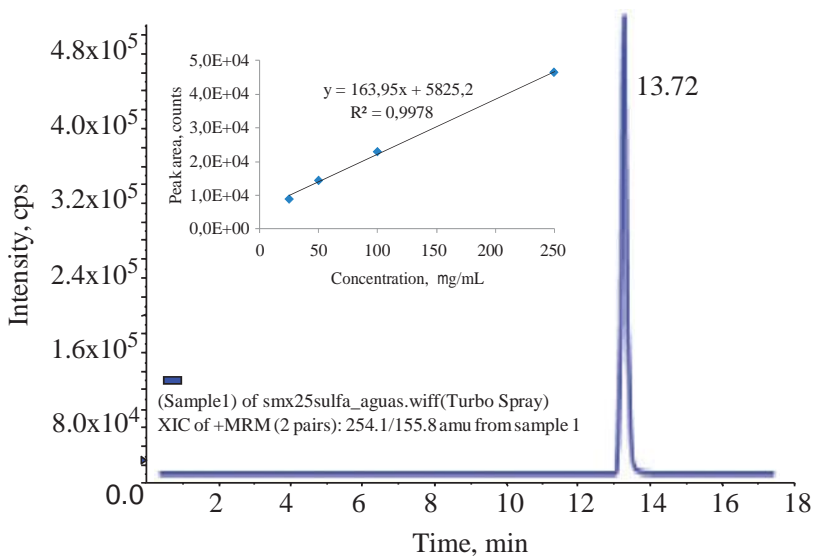

Figure 5. Typical MS chromatogram record for SMX (inset: calibration curve). 
Table 5. Determination of SMX in aquaculture by potentiometric (POT) and the comparison methods (LC-MS/MS).

\begin{tabular}{|c|c|c|c|c|c|c|}
\hline \multirow[b]{2}{*}{ Sample } & \multirow[b]{2}{*}{$\begin{array}{l}\text { Added, } \\
\mathrm{mg} / \mathrm{mL}\end{array}$} & \multicolumn{2}{|c|}{$\operatorname{POT}\left(n \frac{1}{1 / 43}\right)$} & \multirow[b]{2}{*}{$\begin{array}{l}\text { LC_MS/MS } \\
\text { SMX, mg/mL }\end{array}$} & \multirow[b]{2}{*}{ RE (\%) } & \multirow[b]{2}{*}{$\begin{array}{l}\mathrm{RD} \\
(\%)\end{array}$} \\
\hline & & $\mathrm{SMX}, \mathrm{mg} / \mathrm{mL}$ & RE (\%) & & & \\
\hline \multirow[t]{4}{*}{1} & 40 & $39.6 \pm 0.8$ & -2.8 & 44.2 & 10.5 & -10.5 \\
\hline & 100 & $101.8 \pm 0.8$ & 2.3 & 98.5 & -1.5 & 3.3 \\
\hline & 150 & $150.9 \pm 0.2$ & 0.5 & 158.0 & 5.3 & -4.5 \\
\hline & 250 & $245.7 \pm 0.9$ & $-1, .6$ & 241.0 & -3.6 & 2.0 \\
\hline \multirow[t]{4}{*}{2} & 40 & $43.0 \pm 0.5$ & -1.3 & 49.4 & 23.5 & -13.0 \\
\hline & 100 & $102.1 \pm 0.3$ & 2.4 & 97.1 & -2.9 & 5.1 \\
\hline & 150 & $150.3 \pm 1.2$ & -0.7 & 144.0 & -4.0 & 4.4 \\
\hline & 250 & $246.5 \pm 1.6$ & -2.0 & 212.0 & -15.2 & 16.3 \\
\hline \multirow[t]{4}{*}{3} & 40 & $38.6 \pm 0.6$ & -3.2 & 37.2 & -7.0 & 3.7 \\
\hline & 100 & $101.2 \pm 0.7$ & 0.5 & 103.0 & 3.0 & -1.7 \\
\hline & 150 & $149.3 \pm 0.6$ & -0.9 & 143.0 & -4.7 & 4.4 \\
\hline & 250 & $249.2 \pm 0.4$ & -0.3 & 247.0 & -1.2 & 0.9 \\
\hline
\end{tabular}

Table 6. Main chemical parameters of the water samples.

\begin{tabular}{lcccccccc}
\hline & Sample & Sample & Sample & Sample & Sample & Sample & & \\
& 1 & 2 & 3 & 4 & 5 & 6 & Minimum & Maximum \\
\hline Turbidity (UNT) & 50.2 & 50.2 & 50.2 & 50.2 & 0.7 & 0.7 & 50.2 & 0.7 \\
pH (Sorensen scale) & 7.0 & 7.0 & 6.9 & 6.8 & 6.7 & 6.6 & 6.6 & 7.0 \\
Conductivity (mS/cm) & 41.0 & 40.0 & 41.0 & 39.0 & 135.0 & 137.0 & 39.0 & 137.0 \\
Nitrate (mg/L) & 1.4 & 1.3 & 12.4 & 12.7 & 3.9 & 3.9 & 1.3 & 12.7 \\
Nitrite (mg/L) & 50.03 & 50.03 & 50.03 & 0.41 & 50.03 & 0.22 & - & 0.41 \\
Ammonium (mg/L) & 50.05 & 50.05 & 50.05 & 50.05 & 50.05 & 0.34 & 50.05 & 0.34 \\
Sulphate (mg/L) & 1.9 & 2.0 & 8.7 & 8.7 & 1.8 & 1.9 & 1.9 & 8.7 \\
Chloride (mg/L) & 6.3 & 6.4 & 21.2 & 20.5 & 5.9 & 5.9 & 5.9 & 21.2 \\
Fluoride (mg/L) & 51.0 & 51.0 & 51.0 & 51.0 & 51.0 & 51.0 & 51.0 & - \\
Phosphate (mg/L) & 50.03 & 50.03 & 0.12 & 0.11 & 50.03 & 50.03 & 50.03 & 0.12 \\
Iron (mg/L) & 550 & 550 & 550 & 550 & 550 & 550 & 550 & - \\
Potassium (mg/L) & 51.0 & 51.0 & 2.0 & 2.0 & 51.0 & 51.0 & 51.0 & 2.0 \\
Sodium (mg/L) & 5.6 & 5.7 & 14.9 & 15.4 & 4.7 & 4.7 & 5.6 & 15.4 \\
Calcium (mg/L) & 1.6 & 1.6 & 4.8 & 5.1 & 1.5 & 1.5 & 1.5 & 4.8 \\
Magnesium (mg/L) & 51.0 & 51.0 & 3.9 & 3.9 & 51.0 & 51.0 & 51.0 & 3.9 \\
TOC (mg/L) & 51.0 & 51.0 & 51.0 & 51.0 & 51.0 & 51.0 & 51.0 & - \\
Cu (mg/L) & 50.01 & 50.01 & 50.01 & 50.01 & 50.01 & 50.01 & 50.01 & - \\
Zn (mg/L) & 50.1 & 50.1 & 50.1 & 50.1 & 50.1 & 50.1 & 50.1 & - \\
BOD (mg/L) & 53.0 & 53.0 & 53.0 & 53.0 & 53.0 & 53.0 & 53.0 & - \\
COD (mg/L) & 530 & 530 & 530 & 530 & 530 & 530 & 530 & - \\
\hline
\end{tabular}

TOC: total organic content; BOD: biochemical oxygen demand; COD: chemical oxygen demand. 
been pointed out. These levels may be established as known (practical) tolerance limits for future potentiometric application.

\section{Conclusions}

In Mn(III) PPHR sensors an anionic sensor improved the potentiometric response but was not fundamental to obtain a significant emf variation against log SMX concentration, while in CD SMX membrane sensors required the inclusion of an ionic additive. Thus, the corresponding sensors acted, respectively, by a charged or neutral carrier mechanism to produce the potentiometric response. It is possible to exploit a practical application with both of the ionophores and even to attach the corresponding electrodes to the end of a chromatographic column, in case it is found necessary to discriminate several sulphonamides or confirm the existence of a specific sulphonamide.

The proposed electrodes displayed good reproducibility, high sampling rate, wide linear range, low detection limit, high sensitivity and good selectivity. The method is simple, accurate, precise, and inexpensive regarding reagent consumption and equipment involved, for which it is adequate for local screening procedures. It displayed comparable analytical data to a much more sophisticated procure, with much lower cost and shorter time, producing less volume of wastewaters. Furthermore it can be easily applied to the automation of routine determination of SMX in environmental contaminated samples.

\section{Acknowledgements}

The authors wish to thank the financial support from FCT (Fundac, ãopara a Ciência e Tecnologia)/ FEDER, by means of the project PTDC/AGR-AAM/68359/2006 and the PhD grant (SFRH/BD/ 42509/2007) of Almeida SAA.

\section{References}

[1] FAO. The state of world fisheries and aquaculture 2010: Facing challenges and seizing opportunities (Food and Agriculture Organization of the United Nations, Fisheries and Aquaculture Department, Rome, 2010).

[2] R.V. Ribeiro, E.M.F. Reis, C.M.F. Reis, A.C. Freitas-Almeida, and D.P. Rodrigues, Lett. Appl. Microbiol. 51, 611 (2010).

[3] WHO. Antimicrobial Use in Aquaculture and Antimicrobial Resistance: Report of a Joint FAO/ OIE/WHO Expert Consultation on Antimicrobial Use in Aquaculture and Antimicrobial Resistance, Seoul, Republic of Korea, 13-16 June 2006 (Department of Food Safety, Zoonoses dnd Foodborne Diseases, World Health Organization, Geneva, Switzerland, 2006).

[4] P. Smith, Rev. Sci. Tech. 27, 243 (2008).

[5] J. Davies and D. Davies, Microbiol. Molec. Biol. Rev. 74, 417 (2010).

[6] T. Heberer, Toxicol. Lett. 131, 5 (2002).

[7] T. Heberer, J. Hydrol. 266, 175 (2002).

[8] J.E. Renew and C.H. Huang, J. Chromatogr. A 1042, 113 (2004).

[9] X.W. Lu, Z. Dang, and C. Yang, Int. J. Environ. Sci. Tech. 6, 597 (2009).

[10] L. Cao, W. Wang, Y. Yang, C. Yang, Z. Yuan, and S. Xiong, J. Diana, Env. Sci. Pollut. Res. 14, 452(2007)

[11] S. Webb, T. Ternes, M. Gibert, and K. Olejniczak, Toxicol. Lett. 142, 157 (2003). 
[12] M.Y. Haller, S.R. Mü 1ler, C.S. McArdell, A.C. Alder, and M.J.F. Suter, J. Chromatogr. A 952, $111(2002)$.

[13] K. Kummerer, J. Antimicrob. Chemother. 52, 5 (2003).

[14] P.K. Jjemba, Agric. Ecosyst. Environ. 93, 267 (2002).

[15] M.J.G. Gala'n, M.S.D. Cruz, and D. Barcelo', Trends Anal. Chem. 27, 1008 (2008).

[16] T.R. Beam, in Textbook of Pharmacology, edited by C.M. Smith and A.M. Reynard (Saunders, Philadelphia, 1992).

[17] D.P. Baccanari, in Principles of Pharmacology: Basic Concepts and Clinical Applications, edited by P.L. Munson, R.A. Mueller and G.R. Breese (Chapman \& Hall, New York, 1995), pp. 1301-1317.

[18] C. Wu, A.L. Spongberg, and J.D. Witter, Int. J. Environ. Anal. Chem. 88, 1033 (2008).

[19] V.V. Cosofret and R.P. Buck, Crit. Rev. Anal. Chem. 24, 1 (1993).

[20] C.G. Zoski, Handbook of Electrochemistry (The Netherlands, Elsevier, 2007).

[21] M. R. Ganjali, P. Norouzi, M. Rezapour, F. Faridbod, and M.R. Pourjavid, Sensors 6, 1018 (2006).

[22] J.W. Steed, D.R. Turner, K.J. Wallace, Core Concepts in Supramolecular Chemistry and Nanochemistry (John Wiley \& Sons, England, 2007).

[23] A.H. Kamel, M.G.F. Sales, S.A.A. Almeida, and F.T.C. Moreira, Anal. Sci. 25, 365 (2009).

[24] R.P. Buck and V.V. Cosofret, Pure Appl. Chem. 65, 1849 (1993).

[25] R.P Buck and E. Lindner, Pure Appl. Chem. 66, 2527 (1994).

[26] Y. Umezawa, P. Bu“hlmann, K. Umezawa, K. Tohda, and S. Amemiya, Pure Appl. Chem. 72, 1851 (2000).

[27] A. Ceresa, T. Sokalski, and E. Pretsch, J. Electroanal. Chem. 501, 70 (2001).

[28] E. Bakker, P. Bü hlmann, and E. Pretsch, Talanta 63, 3 (2004).

[29] M.G.F. Sales, C.E.L. Amaral, and C.M.D. Matos, Fresenius J. Anal. Chem. 369, 446 (2001).

[30] J.L.F.C. Lima, M.C.B.S.M. Montenegro, and M.G.F. Sales, J. Pharm. Biomed. Anal. 14, 931 (1996).

[31] Y. Qin and E. Bakker, Anal. Chem. 76, 4379 (2004).

[32] I. Beletskaya, V.S. Tyurin, A. Yu, A. Tsivadze, R. Guilard, and C. Stern, Chem. Rev. 109, 1659 (2009).

[33] W. Zhang, E. Rozniecka, E. Malinowska, P. Parzuchowski, and M.E. Meyerhoff, Anal. Chem. 74,4548 (2002).

[34] J. Szejtli, T. Osa, Comprehensive Supramolecular Chemistry, Cyclodextrins, Volume 3 (Elsevier, Oxford, 1996).

[35] K.A. Connors, J. Pharm. Sci. 84, 843 (1995).

[36] E. Bakker and E. Pretsch, Trends Anal. Chem. 21, 11 (2001).

[37] Y. Umezawa, K. Umezawa, and H. Sato, Pure Appl. Chem. 67, 507 (1995).

[38] Decreto lei 236/98 de 1 de Agosto. Lei da Qualidade da água. Dia' rio da Repu' blica - I se' anexo X, 3707-3709. 